\title{
PENDEKATAN HUMANISTIK DALAM PROSES KEGIATAN BELAJAR MENGAJAR PENDIDIKAN AGAMA ISLAM DI SMA NEGERI 1 LUMAJANG
}

\author{
Muhammad Hendra Firmansyah \\ Sekolah Tinggi Ilmu Syari'ah Miftahul Ulum Lumajang \\ Corresponding Author: e-mail: hendrafirmansyah417@gmail.com
}

\begin{abstract}
The humanistic approach views humans as subjects who are free to determine the direction of their lives. Humans are responsible for their own lives and for the lives of others. Humanistic learning theory basically has the aim of learning to humanize humans. Education has many obstacles and very complex problems. Various factors, including the development of science and technology, cause changes in adolescent behavior, especially high school students who commit crimes such as immoral crimes and so on. This moral degradation causes PAI teachers to try to educate students so they don't get carried away by modernization which has a negative impact by instilling religious values. But in reality, many consider PAI lessons to be unimportant. A different phenomenon occurred in one of the high schools in Lumajang, namely SMA Negeri 1 Lumajang. Where students in the teaching and learning process are very enthusiastic to take PAI lessons because PAI learning in schools is carried out with a humanistic approach. This journal discusses the application of a humanistic approach to PAI lessons, the background of PAI teachers using a humanistic approach in the PAI learning process and Barriers to the Application of the Humanistic Approach in the PAI learning process. The research method used is a case study qualitative research method. The results of the research at the Center for Teaching and Learning activities that firstly applying a humanistic approach in the Islamic learning process is one of the efforts of teachers at SMA Negeri 1 Lumajang to improve and develop human values that are free to choose and believe, especially in being creative and thinking. Second, the background of PAI teachers using a humanistic approach in the PAI teaching process, because with this method the enthusiasm of students can be aroused because educators use active learning methods that make students more active and enthusiastic so that the learning process can be maximized. Third, the Barriers to the Implementation of the Humanistic Approach in the PAI learning process, namely these obstacles can come from students, PAI teachers themselves and also from related schools which are still not fully able to create humanist PAI learning in the school environment.
\end{abstract}

Keywords: Approach, Humanistic, Pendidikan Agama Islam

ABSTRAK
Pendekatan humanistik memandang manusia sebagai subyek yang bebas
untuk menentukan arah hidupnya. Manusia bertanggung jawab atas
hidupnya sendiri dan atas hidupnya orang lain. Teori belajar yang
humanistik pada dasarnya memiliki tujuan belajar untuk memanusiakan 
manusia. Pendidikan banyak mengalami kendala dan permasalahan yang amat komplek. Berbagai faktor termasuk perkembangan IPTEK menyebabkan perubahan tingkah laku remaja khususnya siswa/siswi SMA banyak melakukan tindak kriminalitas seperti kejahatan asusila dan sebagainya. Degradasi moral inilah yang menyebabkan guru PAI berusaha untuk mendidik murid agar tidak terbawa dengan arus modernisasi yang membawa dampak negatif dengan menanamkan nilai-nilai keagamaan. Namun pada kenyataannya banyak yang menganggap pelajaran PAI itu tidak penting. Fenomena berbeda terjadi pada salah satu SMA di Lumajang yaitu SMA Negeri 1 Lumajang. Dimana para siswa dalam proses belajar mengajar sangat antusias untuk mengikuti pelajaran PAI karena pembelajaran PAI disekolah tersebut dilakukan dengan pendekatan humanistik. Jurnal ini membahas mengenai implementasi pendekatan humanistik pada pelajaran PAI, Latar belakang guru PAI mengunakan pendekatan humanistik dalam proses pembelajaran PAI dan Hambatan dalam Penerapan Pendekatan Humanistik dalam proses pembelajaran PAI. Metode penelitian yang digunakan adalah metode penelitian kualitatif studi kasus. Hasil dari penelitian di Pusat Kegiatan Belajar mengajar disimpulkan bahwa pertama Implementasi pendekatan humanistik dalam proses pembelajaran Islam merupakan salah satu upaya guru di SMA Negeri 1 Lumajang untuk meningkatkan sekaligus mengembangkan nilai martabat manusia yang bebas memilih dan berkeyakinan, terutama dalam berkreasi dan berpikir. Kedua, Latar belakang guru PAI menggunakan pendekatan humanistik dalam proses mengajar pai, karena dengan metode ini semangat siswa dapat tergugah sebab pendidik menggunakan metode active learning yang membuat siswa lebih aktif dan bersemangat sehingga proses pembelajaran dapat lebih maksimal. Ketiga, Hambatan dalam Penerapan Pendekatan Humanistik dalam proses pembelajaran PAI yaitu Hambatan tersebut dapat berasal dari siswa, guru PAI itu sendiri dan juga dari sekolah terkait yang masih belum sepenuhnya dapat menciptakan pembelajaran PAI yang humanis di lingkungan sekolah.

Kata Kunci : Pendekatan, Humanistik, Pendidikan Agama Islam

\section{PENDAHULUAN}

Pada hakikatnya manusia adalah mahkluk ciptaan Tuhan yang sempurna dibandingkan dengan mahkluk yang lainnya. Manusia adalah makhluk ciptaan Allah yang paling sempurna karena manusia memiliki akal pikiran dan juga hawa nafsu. Disamping itu manusia memiliki naluri dan fitrah, sehingga manusia itu memiliki beberapa kemampuan untuk mengembangkan potensi-potensi yang ada dalam dirinya sebagaimana di Al-Qur'an dalam Surat Ar-Ruum Ayat 30 dan Surat Al-Jastiyah Ayat 13. .(Al-Qur'an Mushhaf Firdausi, 2010).

Pendidikan pada zaman sekarang tentu sangatlah berbeda dengan pendidikan pada zaman dahulu. Perkembangan IPTEK membuat pola pikir manuisa semakin lama semakin berkembang. Perkembangan iptek selain memiliki dampak positif tentunya juga memiliki dampak negatif, yakni merosotnya moral bangsa yang ditunjukkan oleh banyak terjadinya tindak asusila yang dominan dilakukan oleh anak SMA. Hal ini tentu membuat 
para guru resah akan permasalahan ini, beragam usaha dilakukan untuk mengentaskan hal ini salah satunya adalah dengan meningkatkan kualitas pendidikan terutama pada Pendidikan Agama Islam yang memang pada dasarnya mata pelajaran yang mengusung nilai-nilai agamis yang tinggi.

Namun pada kenyataannya mayoritas siswa-siswi pada tingkat Sekolah Menengah Atas tidak jarang memandang sebelah mata pelajaran Pendidikan Agama Islam. Banyak siswa menganggap bahwa Pendidikan Agama Islam tidak begitu penting dibandingkan mata pelajaran umum lainya. Selain itu mereka juga berasumsi bahwa PAI tidak akan dibutuhkan dalam dunia pekerjaan. Hal inilah yang membuat PAI tidak begitu urgen dalam proses pendidikan SMA. (Muhibbinsyah, 2010)

Fenomena berbeda terjadi di SMA Negeri 1 Kota Lumajang. Sekolah ini ada 3 guru PAI yang mampu menyeimbangkan antara mata pelajaran PAI dengan mata pelajaran umum lainnya. Peneliti berasumsi bahwa sekolah ini telah menerapkan pendekatan humanistik dalam proses belajar mengajar PAI. Pendekatan disini dapat diartikan sebagai sudut pandang atau titik tolak terhadap proses belajar mengajar, merujuk pada pandangan mengenai adanya sebuah proses bersifat umum, di dalamnya menginspirasi, mewadahi, melatari metode pembelajaran dengan berbagai cakupan teoritis, dan menguatkan pembelajaran tersebut.

Fokus masalah yang timbul bagaimana implementasi pendekatan humanistik pada pelajaran PAI, Latar belakang guru PAI mengunakan pendekatan humanistik dalam proses pembelajaran PAI dan Hambatan dalam Penerapan Pendekatan Humanistik

Berangkat dari asumsi inilah peneliti mencoba menganalisis pendekatan humanistik dalam pembelajaran PAI di SMA Negeri 1 Lumajang.

\section{METODE PENELITIAN}

Penelitian ini merupakan jenis penelitian kualitatif studi kasus. Sumber datanya merupakan data sekunder yang berasal dari sumber kepustakaan seperti buku, jurnal, dan artikel. Motode analisisnya menggunakan analisis deskriptif.

\section{PEMBAHASAN}

A. Implementasi Teori Humanistik

1. Student Centered Learning adalah proses pembelajaran yang berpusat pada siswa. Proses ini akan mendorong siswa untuk terlibat aktif dalam membangun sikap, perilaku dan pengetahuan. Jika siswa dapat terlibat secara aktif, maka guru tidak akan dapat mengambil hak siswa untuk belajar. Pada sistem pembelajaranini dilakukan dengan metode pembelajaran konstektual, diskusi dan juga pembelajaran discovery. Karena dalam metode-metode ini siswa ditekankan agar aktif dalam belajar.(Ratna Syifa'a Rachmahana, 2008)

2. Humanizing of The Classroom. Berasal dari dua kata yaitu humanizing dan "the classroom" yang artinya memanusiakan dan ruangan kelas. Jadi humanizing the classroom dapat diartikan sebagai 
memanusiakan ruangan kelas. Akan tetapi pengertiannya disini adalah bahwa dalam proses pembelajaran, guru seharusnya memperlakukan peserta didiknya sesuai dengan kondisi dan karakteristiknya mereka masing-masing. Sementara itu, ruangan kelas dapat difungsikan sebagai tempat untuk pembelajaran, sehingga dimanapun proses belajar mengajar terlaksana, baik di luar kelas, di dalam kelas atau bahkan dialam bebas sekalipun, pembelajaran masih tetap terlaksana dengan baik. Jadi dalam penerapannya humanizing the classroom adalah strategi pembelajaran yang diaplikasikan dengan menggunakan pendekatan humanistik, kontekstual learning dan edutainment dimana siswa bisa belajar dari realitas kehidupannya dan lingkungannya serta menciptakan suasana dan perasaan belajar yang menyenangkan. (Arbayah, 2013)

3. Active Learning. Artinya adalah pembelajaran yang aktif. Dengan ini peserta didik diharapkan dapat mengembangkan juga mengenal kemampuan dan potensi yang mereka miliki. Peserta didik juga akan sadar untuk menggunakan potensi dan kemampuan yang mereka miliki di sekitar lingkungan mereka. Mereka akan lebih terlatih untuk berpikir secara krisis dan sistematis, tanggap, terlatih untuk berkarya dan mampu menyelesaikan masalahnya sendiri dengan melakukan penelusuran informasi yang berharga. Active learning ini menekankan agar guru dapat mengajar secara sistematis, bekerja profesional, dan juga mengajar berdasarkan prinsip pembelajaran yang efisien dan efektif. Pendidik boleh melaksanakan model pembelajaran secara sistematis dan menjadikannya pengalaman yang berharga bagi siswa. (Arbayah, 2013)

4. Quantum Learning. Dapat diartikan sebagai petunjuk, strategi dan kiat dalam pembelajaran. Tujuannya untuk mempertajam daya ingat dan pemahaman siswa juga untuk membuat proses pembelajaran menjadi lebih bermanfaat dan menyenangkan. Atau dengan kata lain quantum learning dapat diartikan sebagai model pembelajaran yang fokus untuk memberikan kesenangan pada peserta didik dengan tidak mengindahkan manfaat dari pembelajaran. (Arbayah, 2013)

5. The Accelarated Learning adalah model pembelajaran yang bertujuan untuk menjadikan aktivitas belajar mengajar menjadi aktivitas yang menyenangkan dan tidak membosankan. Model pembelajaran ini adalah model pembelajaran terbaru saat ini yang memberikan beberapa keuntungan karena menekankan untuk menggunakan penelitian tentang perkembangan otak dan belajar anak. Penerapan pembelajaran ini dilakukan dengan media dan metode yang beragam, fleksibel dan juga terbuka.(Arbayah, 2013)

B. Latar Belakang Guru PAI Menggunakan Pendekatan Humanistik dalam Proses Mengajar PAI

Sebagaimana yang ungkapkan oleh Ratna Syifa'a Rachmahana dalam Jurnal Pendidikan Islam El-Tarbawi, bahwa prinsip belajar humanistik menurut Carl Rogers meliputi hasrat untuk belajar, belajar yang berarti, 
belajar tanpa ancaman, belajar atas inisiatif sendiri, dan belajar untuk perubahan.(Ratna Syifa'a Rachmahana, 2008) Alasan guru PAI menggunakan pendekatan humanistik ini beragam salah satunya adalah karena dengan metode ini semangat siswa dapat tergugah sebab pendidik menggunakan metode active learning yang membuat siswa lebih aktif dan bersemangat sehingga proses pembelajaran dapat lebih maksimal. Siswa tidak hanya mendengarkan namun berperan aktif dalam proses pembelajaran. Hal ini akan membuat mereka lebih nyaman dan bersemangat. Keinginan mereka untuk belajar semakin hari akan semakin meningkat. Karena peserta didik ini bebas berpendapat, jadi mereka akan antusias untuk berlomba-lomba memberikan pendapat dan argumennya saat pembelajaran sedang berlangsung. (Abdul Hadis, 2006)

Pembelajaran PAI di SMA Negeri 1 Lumajang ini menggunakan beberapa metode dan model, dimana metode dan model yang di gunakan tersebut mengandung konsep pendekatan humanistik. Guru PAI di SMA ini sangat jarang menggunakan metode ceramah hal ini karena jika menggunakan ceramah maka proses pembelajaran kurang bermakna dan maksimal dengan kata lain para peserta didik akan sibuk dengan dirinya sendiri seperti bermain game atau tidur didalam kelas.

Metode yang digunakan adalah Quantum learning, Snow Bolling, Problem solving, Every One is a Teacher, Diskusi, Tutor sebaya, pembelajaran diluar kelas dan nonton film. Pada masing-masing metodemetode ini memiliki beberapa alasan tersendiri, salah satunya adalah agar siswa-siswi pada saat proses belajar mengajar mampu bergerak aktif alias tidak vakum mendengarkan. Artinya pembelajaran PAI ini berdasarkan pendekatan yang fokus pada peserta didik bukan pada pendidiknya.

Selain itu proses belajar mengajar pendidikan agama Islam di SMA ini juga mengaplikasikan metode pembelajaran sesuai realitas di lingkungan dan kalangan masyarakat. Sehingga peserta didik benar-benar mengenal permasalahan yang sedang terjadi dilingkungan mereka. Agar materi mudah dipahami dengan baik oleh siswa guru di SMA Negeri 1 Lumajang ini sebelum mengajar mereka melihat karakter dan kebutuhan dari siswa itu sendiri. Hal ini untuk mempermudah baik guru maupun siswa itu sendiri dalam menerima materi yang akan dipelajarinya. Pendekatan lainnya yang diaplikasikan adalah pendekatan Tawassul, dimana pendekatan ini adalah temuan baru peneliti saat sedang meneliti dilapangan. Jadi selain menggunakan pendekatan-pendekatan humanis ternyata proses belajar mengajar PAI di SMA Negeri 1 Lumajang ini juga menggunakan pendekatan religius yaitu penekatan Tawassul kepada Nabi Muhammad SAW. Cara yang dilakukan adalah dengan membayangkan wajah orang tua masing-masing siswa dengan harapan pembelajaran materi pada saat itu benar-benar terserap secara maksimal dan bermanfaat bagi anak itu dalam kehidupan sehari-hari di masyarakat.

Penjelasan diatas sesuai dengan apa dijelaskan oleh Muhibbinsyah dalam bukunya yang berjudul psikologi pendidikan bahwa pendekatan pembelajaran yang fokus pada peserta didik itu ada beragam dan salah satunya adalah pendekatan secara konstektual. 
Pendekatan Kontekstual atau Contextual Teaching and Learning (CTL) adalah metode belajar yang membantu pendidik untuk menghubungkan antara materi pembelajaran dengan realitas lingkungan yang mendorong siswa untuk menciptakan relasi antara pengetahuan yang dia punya dengan aplikasi kehidupan sehari-hari dalam lingkungan dan masyarakat. (Muhibbinsyah, 2010)

C. Hambatan dalam Penerapan Pendekatan Humanistik Pada Pembelajaran PAI di SMA Negeri 1 Kota Lumajang

Pencapaian peserta didik dipengaruhi oleh dua faktor utama yakni faktor dalam diri sendiri dan yang kedua adalah faktor eksternal seperti faktor lingkungan. Faktor diri sendiri adalah kemampuan yang ada pada diri siswa itu sendiri dan berpengaruh besar terhadap hasil belajar yang akan dicapai. Seperti apa yang telah dikemukakan oleh Clark bahwa hasil belajar siswa di sekolah adalah 30\% dipengaruhi oleh lingkungan dan 70\% dipengaruhi oleh kemampuan siswa.(Nana Sudiana, 2007)

Pembelajaran PAI pada kenyataannya mengalami hambatan yang dihadapi oleh tenaga pendidik PAI. Hambatan tersebut dapat berasal dari siswa, guru PAI itu sendiri dan juga dari sekolah terkait yang masih belum sepenuhnya dapat menciptakan pembelajaran PAI yang humanis di lingkungan sekolah. Hal ini ditegaskan dengan adanya beberapa peserta didik yang merasa kurang maksimal ketika proses belajar mengajar berlangsung. Namun mayoritas dari mereka para siswa telah mengatakan bahwa pembelajaran PAI yang selama ini mereka terima berjalan dengan penuh makna dan menyenangkan tanpa kekerasan dalam bentuk apapun.

Adapun faktor-faktor yang mempengaruhi keberhasilan pembelajaran secara umum adalah sebagai berikut: (Asri Budiningsih, 2012)

1. Tujuan

Tujuan yang pasti dari pembelajaran melatarbelakangi perumusan tujuan pengajar dan menjadi tolak ukur untuk keberhasilan pengajaran.

2. Guru

Karakter dan kepribadian pendidik yang kompeten dan diakui menjadi aspek penting dari keberhasilan pembelajaran untuk membawa peserta didiknya menjadi siswa yang tidak hanya berilmu namun juga memiliki akhlak dan kepribadian yang baik.

3. Anak didik

Jumlah siswa dalam satu kelas juga akan mempengaruhi pengelolaan pembelajaran dalam kelas yang akan berpengaruh pada proses belajar mengajar. Daya serap siswa yang berbeda menjadi tolak ukur untuk hal ini, karena itu harus dikenal tingkatan keberhasil pembelajaran yakni keberhasilan minimal, maksimal hingga optimal.

4. Kegiatan pengajaran

Beragam aplikasi metode mengajar akan menghasilkan pembelajaran yang berbeda kualitasnya. Penggunann metode pembelajaran bertujuan untuk pengajaran guru yang akan mempengaruhi tinggi rendahnya keberhasilan dari proses pembelajaran itu sendiri. 
5. Bahan dan alat evaluasi

Bahan untuk ujian adalah bahan yang ada didalam kurikulum yang dipastikan sudah dipelajari ole peserta didik untuk kepentingan ulangan mereka. Sebelum ujian bahan pelajaran tersebut haruslah selesai. Jika alat evaluasi tidak valid, maka evaluasi tersebut tidak dapat digunakan untuk mengukur tingkat keberhasilan pembelajaran para peserta didik.

6. Suasana evaluasi

Dalam hal ini pendidik harus dengan serius memeriksa satu persatu anak didiknya agar tidak mencontek dan untuk berlaku jujur dalam proses ujian.

7. Faktor-faktor peningkatan mutu pendidikan

a. Faktor tujuan pendidikan

b. Faktor masukan atau Input pendidikan

c. Faktor manajemen dan supervisi pendidikan

d. Faktor personal pendidikan (siswa, guru, kepala sekolah, pengawas dan staff sekolah.)

e. Faktor sarana dan prasarana pendidikan (Kurikulum, fasilitas, peralatan, gedung, perpustakaan)

f. Faktor Intansional (semua pihak yang terkait dengan pelaksanaan pendidikan misalny orang tua, pemda)

g. Faktor tekhnologi, seni dan ilmu pengetahuan yang dipelajari peserta didik.

Beberapa hal dapat mempengaruhi proses belajar mengajar PAI seperti motivasi dari peserta didik itu sendiri ataupun dorongan psikologis dari orang tuanya. Disamping itu fasilitas sekolah juga berperan penting dalam proses belajar mengajar. Lebih jauh dari itu peran penting kepala sekolah dalam hal ini juga sangat berpengaruh. Semua aspek penting dalam sekolah akan memberikan efek positif terhadap berlangsungnya proses belajar mengajar PAI.

8. Keefektifan

Proses belajar mengajar efektif jika dapat menambah atau memberikan pengetahuan baru dan informasi bagi siswa. Keefektifan pembelajaran dapat dilihat dengan kriteria :

a. Kecermatan penguasaan perilaku atau kemampuan yang dipelajari

b. Kesesuaian dengan sistematika kegiatan belajar mengajar yang harus dilaksanakan

c. Kecepatan unjuk kerja sebagai bentuk hasil belajar

d. Kualitas hasil akhir yang dapat dicapai

e. Kuantitas unjuk kerja sebagai bentuk hasil belajar

f. Tingkat retensi belajar

9. Efisiensi

Merupakan pembelajaran yang menggairahkan, menyenangkan dan mampu memberikan motivasi bagi peserta didik dalam belajar, sehingga pendidik harus bisa menciptakan sesuatu yang baru dalam proses belajar mengajar agar peserta didik tidak merasa bosan saat belajar. 
10. Daya tarik

Daya tarik dapat dilihat dengan mengamati kecendurungan atau semangat siswa untuk belajar. Siswa harus dimotivasi agar senang terhadap pelajaran pendidikan agama Islam. Karena akhir-akhir ini PAI dianggap kurang bermanfaat yang menjadikan minat siswa berkurang untuk mempelajarinya. Pelajaran yang dianggap penting dan populer yang diminati banyak siswa sehingga mengabaikan pentingnya pelajaran pendidikan agama Islam.

Berdasarkan temuan peneliti dan teori diatas dapat disimpulkan bahwa setiap pembelajaran pasti mengalami sebuah hambatan-hambatan baik itu dalam dalam diri siswa itu maupun di luar siswa itu seperti lingkungan sekolah dan keluarga yang didalamnya ada guru dan kependidikan.

\section{PENUTUP}

Implementasi pendekatan humanistik dalam proses pembelajaran Pendidikan Agama Islam merupakan salah satu upaya guru di SMA Negeri 1 Lumajang untuk meningkatkan sekaligus mengembangkan nilai martabat manusia yang bebas memilih dan berkeyakinan, terutama dalam berkreasi dan berpikir. Latar belakang Guru PAI Menggunakan Pendekatan Humanistik dalam Pembelajaran Pendidikan Agama Islam di SMA Negeri 1 Lumajang Pembelajaran berjalan lebih bermakna, siswa merasa nyaman, ceria, senang dan merasa dihargai kemampuannya serta membuat siswa aktif.

Latar belakang guru PAI menggunakan pendekatan humanistik dalam proses mengajar pai Pembelajaran ini karena dengan metode ini semangat siswa dapat tergugah sebab pendidik menggunakan metode active learning yang membuat siswa lebih aktif dan bersemangat sehingga proses pembelajaran dapat lebih maksimal. Siswa tidak hanya mendengarkan namun berperan aktif dalam proses pembelajaran.

Hambatan Yang Dihadapi dalam Penerapan Pendekatan Humanistik Pada Pembelajaran Pendidikan Agama Islam di SMA Negeri 1 Lumajang dan Cara Mengatasinya adalah Hambatan tersebut dapat berasal dari siswa, guru PAI itu sendiri dan juga dari sekolah terkait yang masih belum sepenuhnya dapat menciptakan pembelajaran PAI yang humanis di lingkungan sekolah. Hal ini dengan adanya beberapa peserta didik yang merasa kurang maksimal ketika proses belajar mengajar berlangsung. Namun mayoritas dari mereka para siswa telah mengatakan bahwa pembelajaran PAI yang selama ini mereka terima berjalan dengan penuh makna dan menyenangkan tanpa kekerasan dalam bentuk apapun Upaya mengatasinya adalah dengan berkolaborasi dengan pihak BK, menjalin komunikasi dengan orang tua siswa dan konsultasi dengan kepala sekolah. 


\section{DAFTAR PUSTAKA}

Assegaf, Rachman. (2011). Filsafat Pendidikan Islam, Paradigma Baru Pendidikan Hadhari Berbasis Integratif-Interkonektif. Jakarta: PT. Raja Grafindo Persada.

Baharuddin dan Makin, Moh. (2009). Pendidikan Humanistik, Konsep, Teori, dan Aplikasi Praktis dalam Dunia Pendidikan. Yogyakarta: ARRuzzmedia, 2009

Budiningsih, Asri. (2012). Belajar dan Pembelajaran. Jakarta: PT Rikena Cipta, 2012.

Dakir. (1993). Dasar-dasar Psikologi. Jakarta: Pustaka Pelajar, 1993

Firmansyah, Wahyu. (2012). Skripsi, Penggunaan Pendekatan Humanistik Model Mangunwijaya Untuk Meningkatkan Aktivitas Dan Hasil Belajar Sains. Malang: UM Malang

Hadis, Abdul. (2006). Psikologi Dalam Pendidikan. Bandung: Alfabeta.

Hasan, Ali, dan Ali, Mukti. (2009). Kapita Selekta Pendidikan Islam. Jakarta: Pedoman Ilmu Jaya.

Hidayat, Nurul. (2010). Al-Qur'an Mushhaf Firdausi, Terjemahan Kemenag RI. Bandung :Terjemahan Kemenag RI

Muhaimin. (2008). Paradigma Pendidikan Islam (Upaya Mengefektifkan Pendidikan Agama Islam di Sekolah. Bandung: PT Remaja Rosdakarya

Muhibbinsyah. (2010). Psikologi Pendidikan. Bandung : PT Remaja Rosdakarya

Syifaâ, R. (2008). Psikologi humanistik dan aplikasinya dalam pendidikan. EL TARBAWI, 1(1), 99-114.

Sudiana, Nana. (2007). Dasar-dasar Proses Belajar Mengajar. (Bandung: PT Sinar Baru Algensindo.

Sukmadinata dan Syaodih, Nana. (2007). Landasan Psikologi Proses Pendidikan. Bandung: Cet. IV, Remaja Rosdakarya.

Sanusi, U. (2013). Pembelajaran dengan Pendekatan Humanistik (Penelitian pada Mts Negeri Model Cigugur Kuningan). taklim, 355. 